\title{
Inter-pregnancy interval and pregnancy outcome
}

\author{
Archana Chandna*, Rita Mittal, Anoopa Sood, Pranav Sood
}

Department of Obstetrics \& Gynaecology, IGMC, Shimla, India

Received: 08 December 2015

Accepted: 23 January 2016

\section{*Correspondence:}

Dr. Archana Chandna,

E-mail: archanachandna@gmail.com

Copyright: (C) the author(s), publisher and licensee Medip Academy. This is an open-access article distributed under the terms of the Creative Commons Attribution Non-Commercial License, which permits unrestricted non-commercial use, distribution, and reproduction in any medium, provided the original work is properly cited.

\begin{abstract}
Background: Obstetricians are often presented with questions regarding the optimal Inter-pregnancy interval (IPI), especially by women who had a spontaneous abortion. They often desire to conceive again with minimal delay.

Methods: A study was conducted on $252,2^{\text {nd }}$ gravida women with history of previous spontaneous abortion. Based on their IPI women were divided into 5 groups.

Results: Most of the pregnancy complications like threatened miscarriage, premature rupture of membranes (PROM), diabetes, pre-eclampsia, preterm delivery, placental abruption, caesarean section and post-partum hemorrhage (PPH) were maximum in those who conceived after 24 months and least in those who conceived between 6-12 months. But intra uterine growth restriction (IUGR) was more in early conception group. Pregnancy outcome was also good in those who conceived within 6 months.

Conclusions: Women who conceive between 6-12 months of an initial miscarriage have better outcomes and lower complication rates in their subsequent pregnancy. Based on the results, we support the recommendation of WHO that after an abortion, women should wait for at least 6 months before becoming pregnant again in order to prevent adverse perinatal and maternal outcomes in the subsequent pregnancy. As the pregnancy outcome is also good in those who conceived within 6 months, women wanting to conceive immediately due to increasing age or anxiety should not be discouraged and allowed to conceive.
\end{abstract}

Keywords: Inter pregnancy interval, Pregnancy complications

\section{INTRODUCTION}

Any miscarriage is associated with distress and prompts questions about the optimal timing of the next pregnancy. How long a couple should wait before trying for another pregnancy after a miscarriage is controversial. ${ }^{1}$ Any delay in attempting conception could further decrease the chances of a healthy baby. The adverse effects of advancing age should be balanced against delaying subsequent pregnancies and advice should be tailored to the needs of individual women. Women wanting to become pregnant soon after a miscarriage should not be discouraged. There may be cases where a delay is desirable, for example if there are signs of infection, and women should be advised appropriately. ${ }^{2}$ Keeping all the above facts in mind we conducted a study in our department to determine whether the length of the interval between an abortion and next pregnancy is associated with increased risk of adverse pregnancy outcomes. Inter pregnancy interval (IPI) was calculated as the time period between last abortion and Last menstrual period (LMP) of the present pregnancy.

\section{METHODS}

We conducted a one year study in department of OBG, $\mathrm{KNH}$, IGMC, Shimla. $2^{\text {nd }}$ gravida women with history of abortion in the previous pregnancy coming after 20 weeks of pregnancy were included. Their IPI were noted. All the antenatal, intrapartum and postpartum complications were recorded. Their modes of delivery were studied. Any poor neonatal outcome was also noted. 
Women were followed till discharge from hospital. There were total of 252 patients in the study group.

\section{Exclusion criteria}

- Women with history of induced abortion.

- Women with twin pregnancy because these women are as such high risk and complications might be because of twin gestation itself and not because of previous abortion.

\section{RESULTS}

Out of 252, 60 women $(23.8 \%)$ conceived within 6 months of previous miscarriage, $73(29.0 \%)$ conceived between 6 to 12 months, 35 (13.9\%) conceived between 13 to 18 months, $37(14.7 \%)$ between 19 to 24 months, $47(18.6 \%)$ conceived after 24 months (Table 1).

In the present study, most of the pregnancy complications like threatened miscarriage, PROM, Diabetes, pre- eclampsia, preterm delivery and placental abruption are more common in late conceptions (>24 months) and least in those who conceived between 6-12 months. They are also less in women who conceived within 6 months. There was no case of placental abruption in women who conceived within 6 months and between 13-18 months of previous abortion. But IUGR is more in early conception group i.e. ( $<6$ and 6-12 months) (Table 2). It is observed that induction rate is highest in women who conceived between 19-24 months (45.9\%) and least in those who conceived between 6-12 months. More number of babies was delivered by caesarean section in $>24$ months group (36.2\%). Out of 60 women who conceived within 6 months, only $4(6.6 \%)$ underwent caesarean section. Caesarean rate was also less $(12.3 \%)$ in women who conceived between 6-12 months. The incidence of PPH was maximum in late conceptions i.e. $>24$ months $(9.6 \%)$ but it is also high in those who conceived within 1 year of previous abortion $(6.5 \%)$ (Table 3 ).

Table 1: Distribution of subjects.

\begin{tabular}{|c|c|c|c|c|c|c|c|c|c|c|}
\hline \multicolumn{11}{|c|}{ IPI (Months) } \\
\hline & \multicolumn{2}{|c|}{$<6$ Months } & \multicolumn{2}{|c|}{ 6-12 Months } & \multicolumn{2}{|c|}{ 13-18 Months } & \multicolumn{2}{|c|}{ 19-24 Months } & \multicolumn{2}{|c|}{$>24$ Months } \\
\hline & No & $\%$ & No & $\%$ & No & $\%$ & No & $\%$ & No & $\%$ \\
\hline Subjects & 60 & 23.8 & 73 & 29.0 & 35 & 13.9 & 37 & 14.7 & 47 & 18.6 \\
\hline
\end{tabular}

Table 2: Pregnancy complications.

\begin{tabular}{|c|c|c|c|c|c|c|c|c|c|c|c|}
\hline \multirow{5}{*}{$\begin{array}{l}\text { S. } \\
\text { No }\end{array}$} & \multirow{5}{*}{$\begin{array}{l}\text { Pregnancy } \\
\text { Comp }\end{array}$} & \multicolumn{10}{|c|}{ IPI (months) } \\
\hline & & \multicolumn{2}{|c|}{$<6$} & \multicolumn{2}{|c|}{$6-12$} & \multicolumn{2}{|c|}{$13-18$} & \multicolumn{2}{|c|}{$19-24$} & \multicolumn{2}{|c|}{$>24$} \\
\hline & & \multicolumn{10}{|c|}{ Total No of cases } \\
\hline & & \multicolumn{2}{|c|}{60} & \multicolumn{2}{|l|}{73} & \multicolumn{2}{|l|}{35} & \multicolumn{2}{|l|}{37} & \multicolumn{2}{|l|}{47} \\
\hline & & No & $\%$ & No & $\%$ & No & $\%$ & No & $\%$ & No & $\%$ \\
\hline 1. & Threatened miscarriage & 7 & 11.7 & 7 & 9.6 & 6 & 17.1 & 6 & 16.2 & 12 & 25.5 \\
\hline 2. & PROM & 11 & 18.1 & 7 & 9.6 & 11 & 31.4 & 4 & 11.1 & 15 & 31.9 \\
\hline 3. & IUGR & 5 & 8.2 & 6 & 8.2 & 2 & 5.7 & 4 & 11.1 & 3 & 6.4 \\
\hline 4. & Diabetes & 1 & 1.6 & 1 & 1.4 & 0 & 0.0 & 2 & 5.4 & 4 & 8.5 \\
\hline 5. & Abruption & 0 & 0.0 & 4 & 5.5 & 0 & 0.0 & 1 & 2.8 & 4 & 8.5 \\
\hline 6. & Placenta praevia & 2 & 3.3 & 1 & 1.4 & 0 & 0.0 & 0 & 0.0 & 1 & 2.1 \\
\hline 7. & Pre-eclampsia & 2 & 3.3 & 0 & 0.0 & 0 & 0.0 & 4 & 11.1 & 2 & 4.3 \\
\hline 8. & Preterm delivery & 4 & 6.7 & 4 & 5.5 & 6 & 17.1 & 2 & 5.4 & 13 & 27.7 \\
\hline
\end{tabular}

Table 3: Labour events.

\begin{tabular}{|c|c|c|c|c|c|c|c|c|c|c|c|}
\hline \multirow{5}{*}{$\begin{array}{l}\text { S. } \\
\text { No }\end{array}$} & \multirow{5}{*}{ Labour events } & \multicolumn{10}{|c|}{ IPI (Months) } \\
\hline & & \multicolumn{2}{|c|}{$<6$} & \multicolumn{2}{|c|}{$6-12$} & \multicolumn{2}{|c|}{$13-18$} & \multicolumn{2}{|c|}{$19-24$} & \multicolumn{2}{|c|}{$>24$} \\
\hline & & \multicolumn{10}{|c|}{ Total No of cases } \\
\hline & & \multicolumn{2}{|c|}{60} & \multicolumn{2}{|l|}{73} & \multicolumn{2}{|l|}{35} & \multicolumn{2}{|l|}{37} & \multicolumn{2}{|l|}{47} \\
\hline & & No & $\%$ & No & $\%$ & No & $\%$ & No & $\%$ & No & $\%$ \\
\hline 1. & Induction of labour & 24 & 40.0 & 18 & 24.7 & 12 & 34.3 & 17 & 45.9 & 18 & 38.3 \\
\hline 2. & Caesarean section & 4 & 6.6 & 9 & 12.3 & 9 & 25.7 & 5 & 13.5 & 17 & 36.2 \\
\hline 3. & PPH & 3 & 6.5 & 5 & 6.8 & 1 & 2.9 & 2 & 2.8 & 4 & 9.6 \\
\hline
\end{tabular}


Table 4: Neonatal outcome.

\begin{tabular}{|c|c|c|c|c|c|c|c|c|c|c|c|}
\hline \multirow{5}{*}{$\begin{array}{l}\text { S. } \\
\text { No }\end{array}$} & & \multicolumn{10}{|c|}{ IPI (Months) } \\
\hline & & $<6$ & & $6-1$ & & $13-$ & & $19-2$ & & $>24$ & \\
\hline & & \multicolumn{10}{|c|}{ Total No of cases } \\
\hline & & \multicolumn{2}{|c|}{60} & \multicolumn{2}{|l|}{73} & \multicolumn{2}{|l|}{35} & \multicolumn{2}{|l|}{37} & \multicolumn{2}{|l|}{47} \\
\hline & & No & $\%$ & No & $\%$ & No & $\%$ & No & $\%$ & No & $\%$ \\
\hline 1. & 1 min Apgar $<7$ & 4 & 6.7 & 1 & 1.4 & 4 & 11.4 & 2 & 5.4 & 8 & 17.0 \\
\hline 2. & 5 min Apgar $<7$ & 3 & 5.0 & 1 & 1.4 & 3 & 8.6 & 1 & 2.7 & 5 & 10.6 \\
\hline 3. & Admission to NICU & 5 & 8.3 & 6 & 8.2 & 4 & 11.4 & 2 & 5.4 & 8 & 17.0 \\
\hline 4. & Perinatal mortality & 1 & 1.7 & 2 & 2.7 & 3 & 8.6 & 0 & 0.0 & 4 & 8.5 \\
\hline 5. & Congenital anomalies & 2 & 3.3 & 3 & 4.1 & 2 & 5.7 & 0 & 0.0 & 2 & 4.2 \\
\hline
\end{tabular}

Table 4, shows that low apgar scores are seen more in babies whose mothers conceived after 24 months $(17.0 \%$ and $10.6 \%$; $1 \mathrm{~min}$ and $5 \mathrm{~min}$ respectively), while only (1.4\%) of babies had low apgar score (both 1 and $5 \mathrm{~min}$ ) whose mothers conceived between 6-12 months. $17.0 \%$ of babies were admitted to neonatal intensive care unit (NICU) in the late conception group (i.e. >24 months). While only $8.2 \%$ in 6-12 months group. It was also less in those who conceived within 6 months $(8.3 \%)$. Perinatal mortality is maximum who conceived between 13-18 months $(8.6 \%)$ and also more in $>24$ months $(8.5 \%)$. There was no perinatal mortality in 18-24 months group. Perinatal mortality was just $1.7 \%$ in those who conceived within 6 months. Incidence of congenital anomalies is maximum in 13-18 months $(5.7 \%)$ and least in those who conceived within 6 months $(3.3 \%)$. The anomalies which were observed during the study were neural tube defect, cleft lip and patent ductus arteriosus.

\section{DISCUSSION}

In the present study incidence of IUGR is least in women who conceived between 13-18 months and maximum in those who conceived between 19-24 months. Our study is in contrast to the study by Agudelo et al who have shown least risk in 19-24 months group. It is also in contrast to the study by Love et al who showed least incidence in group conceived within 6 months and maximum in those conceived after 24 months. $^{2,3}$ A study by Basso et al states that risk of IUGR increases with increasing IPI. ${ }^{3,4}$ Incidence of diabetes is maximum $(8.5 \%)$ in women who conceived after 24 months. Agudelo et al has also shown similar results. ${ }^{3}$ The increased incidence after 24 months can be attributed to the increasing age of the mother with increasing IPI. Elderly women are at increased risk of diabetes compared to younger women particularly so of Asian/Indian origin. No significant association was found between IPI and risk of placental abruption, placenta praevia and eclampsia. It is comparable to the study by Love et al and Agudelo et al who have reported similar results. ${ }^{2,3}$ Incidence of pre-eclampsia is least in the group conceived between 6-12 months and 13-18 months and maximum in 19-24 months group. Somewhat similar results were shown by Rud B and Klunder K. ${ }^{5}$ They reported increased incidence $(13.6 \%)$ in conception after 26 months and only $5.3 \%$ within 12 months. While Agudelo et al and Love et al reported no association between IPI and risk of pre-eclampsia. ${ }^{2,3}$ Possible explanation for increased risk of pre-eclampsia after long IPI is physiology of a mother who becomes pregnant after a long interval is similar to that of a woman who is pregnant for the first time which in itself is a risk factor for pre-eclampsia. Present study shows that, both early and late preterm deliveries are more common in late conception group i.e. $>24$ months. This study is similar to the study by Love et al who also have reported maximum incidence in late conception group for both early and late preterm deliveries. ${ }^{2}$ It is also comparable to the study by Basso et al who reported increased incidence of preterm delivery with increasing IPI. ${ }^{4}$ Whereas a study by Agudelo et al and Rodrigues et al have shown opposite results. $^{5,6}$ They have reported a significant association between short interpregnancy interval ( $<6$ months) and spontaneous early preterm delivery. Induction of labour is least $(24.7 \%)$ in women who conceived between 6-12 months and maximum $(45.9 \%)$ in those who conceived between 19-24 months. Love et al also reported maximum induction rate $(29.7 \%)$ in $19-24$ months group and similar induction rates in rest of the groups. ${ }^{2}$ In the present study, caesarean rate is least in women who conceived within 6 months and maximum in those who conceived after 24 months. A study by Love et al has shown similar results. ${ }^{2}$ Increased caesarean rate in late conception group may be because of other associated complications. Risk of PPH is maximum in women who conceived after 24 months and least in 13-18 and 19-24 months group. However the difference is insignificant. It is comparable to the study by Agudelo et al also showed no significant association between the incidence of PPH and IPI. Adverse perinatal outcomes in the form of, low apgar scores, birth asphyxia and admission to NICU were more in late conception group ( $>24$ months) and least in 6-12 months group. ${ }^{3}$ They were also less in babies whose mothers conceived within 6 months. There was no case of 
perinatal mortality or any congenital malformation in the 19-24 months group. They were also less in those who conceived within 6 months or 6-12 months compared to other two groups. A study by Agudelo et al has compared only the apgar score and found no association between IPI and low apgar score.

\section{CONCLUSIONS}

Women who conceive between 6-12 months of an initial miscarriage have better outcomes and lower complication rates in their subsequent pregnancy. Based on the results, we support the recommendation of WHO that after an abortion, women should wait for at least 6 months before becoming pregnant again in order to prevent adverse perinatal and maternal outcomes in the subsequent pregnancy. As the pregnancy outcome is also good in those who conceived within 6 months, women wanting to conceive immediately due to increasing age or anxiety should not be discouraged and allowed to conceive.

Funding: No funding sources Conflict of interest: None declared

Ethical approval: The study was approved by the Institutional Ethics Committee

\section{REFERENCES}

1. Paz JE, Locasotano, Gadow EC, Castilla EE. Previous miscarriage and still birth as risk factors for other unfavorable outcomes in the next pregnancy. Br J Obstet Gynecol. 1992;99:808-12.

2. Love ER, Bhattacharya S, Smith NC. Effect of interpregnancy interval on outcomes of pregnancy after miscarriage. British Medical Journal. 2010;341:c3967.

3. Agudelo AC, Beliza JM, Breman R, Brockman SC, Bermudez AR. Effect of the interpregnancy interval after an abortion on maternal and perinatal health in Latin America. International Journal of Gynaecology and Obstetrics. 2005;89:534-40.

4. Basso O, Olsen J and Christensen K. Risk of preterm delivery, low birth weight and growth retardation following spontaneous abortion. International Journal of Epidemiology. 1998;27:642-6.

5. Rud B, Klunder $K$. The course of pregnancy following spontaneous abortion. Acta Obstet Gynecol Scand. 1985;64:277-8.

6. Rodrigues T, Barros H. Short interpregnancy interval and risk of spontaneous preterm delivery. European Journal of Obstetrics \& Gynecology and Reproductive Biology. 2008;136:184-8.

Cite this article as: Chandna A, Mittal R, Sood A, Sood P. Inter-pregnancy interval and pregnancy outcome. Int J Reprod Contracept Obstet Gynecol 2016;5:415-8. 